\title{
Possible roles of the cAMP-mediators EPAC and RAP1 in decidualization of rat uterus
}

\author{
Kazuya Kusama, Mikihiro Yoshie, Kazuhiro Tamura, Takiko Daikoku, \\ Tsutomu Takarada and Eiichi Tachikawa \\ Department of Endocrine and Neural Pharmacology, Tokyo University of Pharmacy and Life Sciences, \\ 1432-1 Horinouchi, Hachioji, Tokyo 192-0392, Japan and ${ }^{1}$ Division of Reproductive Sciences, Perinatal Institute, \\ Cincinnati Children's Hospital Medical Center, 3333 Burnet Avenue, Cincinnati, Ohio 45229-3026, USA
}

Correspondence should be addressed to M Yoshie; Email: yoshie@toyaku.ac.jp or to K Tamura; Email: hiro@toyaku.ac.jp

\begin{abstract}
The optimal decidualization of endometrial stromal cells (ESCs) following embryo implantation is one of the critical steps to establish pregnancy in rodents and humans. This step is intricately regulated by ovarian hormones. Using in vitro human ESCs model, we previously showed that activation of a cAMP mediator, exchange protein directly activated by cAMP (EPAC), promotes ovarian steroid- or cAMP analog-induced decidualization. However, expressions and functions of EPAC and RAP1 in the uterus during pregnancy have not yet been examined. In this study, we found that the expression of EPAC2 and RAP1 was markedly upregulated in the decidual cells at the implantation sites on days 7 and 9 of pregnancy in rats. Furthermore, both delayed-implantation and artificial decidualization models showed that EPAC2 and RAP1 expression was enhanced in decidual cells. Significant activation of cAMP-responsive element-binding protein (CREB), a central transcriptional factor of cAMP signaling, was observed in decidual cells. These spatiotemporal expressions of protein related EPAC pathway are overlapped by sites with activated CAMP signaling, indicating the association of EPAC signaling with decidualization. Strikingly, further studies in in vitro rat decidualization model showed that the cAMP analog and medroxyprogesterone stimulated the expression of decidual markers, while knockdown of EPAC1/2 and RAP1 attenuated the expressions of these markers. Together, these findings suggest that EPAC and RAP1 are the crucial factors for endometrial decidualization in rat pregnancy.

Reproduction (2014) 147 897-906
\end{abstract}

\section{Introduction}

Embryo implantation and appropriate uterine stromal cells differentiation into decidual cells (decidualization) are the indispensable steps for the establishment of pregnancy in primate and murine species. Both embryo attachment and the decidualization during peri-implantation are stringently regulated by the ovarian steroids, estradiol-17 $\beta\left(\mathrm{E}_{2}\right)$ and progesterone $\left(\mathrm{P}_{4}\right)$ (Cross et al. 1994, Carson et al. 2000). $\mathrm{E}_{2}$ directs the proliferation of uterine epithelial cells, while in the stroma this process requires both $\mathrm{P}_{4}$ and $\mathrm{E}_{2}$ (Dey et al. 2004). In rats, a nidatory surge of estrogen on day 5 of pregnancy is essential for the initiation of implantation (Paria et al. 2001). After attachment, epithelial cells undergo apoptosis, while stromal cells enter into a process of extensive proliferation and decidualization at the site of blastocyst apposition (Cross et al. 1994). The major difference in decidualization between rodents and humans is that attachment of the blastocyst is required in rodents for uterine decidualization (Lim \& Wang 2010). Despite this difference, the hormonal requirements necessary for decidualization and the behavior of endometrial cells during decidualization are thought to be similar in rodents and humans (Lim \& Wang 2010).

Exchange protein directly activated by cAMP (EPAC) is a mediator of CAMP signaling that is distinct from protein kinase A (PKA) (Kawasaki et al. 1998, de Rooij et al. 1998). EPAC has two isoforms, EPAC1 and EPAC2, which are also known as Rap guanine nucleotide exchange factor (RapGEF) 3 and 4, respectively, and is a GEF for small GTPases in the Ras family which includes RAP proteins. Binding of cAMP to the cyclic nucleotidebinding domain of EPAC causes conformational changes that allow the recruitment of the RAP protein to the CDC25 homology domain of EPAC and conversion of the GDP-bound inactive form of Rap to the GTP-bound active form (Bos 2006). RAP1 is an isoform of RAP protein, and EPAC/RAP1 pathway involves in the regulation of cell adhesion, secretion, proliferation, or differentiation (Ahn et al. 2006, Kooistra et al. 2007). In fact, our previous studies showed that EPAC/RAP1 pathway involves differentiation in uteri during pregnancy. For examples, EPAC1/RAP1 pathway promotes 
the differentiation of cytotrophoblasts into syncytiotrophoblasts (Yoshie et al. 2010). Another example is that, during the decidualization of human endometrial stromal cells (ESCs), EPAC/RAP1 signaling enhanced prolactin (PRL) and insulin-like growth factor-binding protein 1 (IGFBP1) expression induced by ovarian steroids and CAMP analogs, while siRNA-mediated silencing of EPAC1, EPAC2, or RAP1 inhibited the expression of PRL and IGFBP1 and morphological differentiation (Kusama et al. 2013). However, we observed expressions and functions of EPAC/RAP1 only in vitro.

To further explore the physiological significance of EPAC and its downstream factors in decidualization, especially in vivo, we examined the expression of EPAC1/2 and RAP1 in peri-implantation uteri during pregnancy, in the delayed-implantation model, and in the artificially induced decidualization model in rats. Using rat ESCs in vitro, we further examined the functional role of these mediators in decidualization.

\section{Materials and methods}

\section{Reagents}

$\mathrm{P}_{4}, \mathrm{E}_{2}$, medroxyprogesterone acetate (MPA), and dibutyryl cAMP (db-cAMP) were purchased from Sigma-Aldrich. An Epac-selective activator, 8-(4-chlorophenyltio)-2'-O-methyl cAMP (CPT), and a PKA-selective activator, $\mathrm{N}^{6}$-phenyl-cAMP (Phe), were purchased from Biolog Life Science Institute (Bremen, Germany). An antibody against Epac1 (ab21235) was purchased from Abcam (Cambridge, MA, USA). Antibodies against Epac2 (sc-25633) and Rap1 (sc-65) were purchased from Santa Cruz Biotechnology. An antibody against p-CREB (87G3) was purchased from Cell Signaling Technology (Beverly, MA, USA). Antibodies against cyclin D3 (DCS-22) and $\beta$-actin (clone AC-15) were purchased from Sigma-Aldrich.

\footnotetext{
Animals

Adult Wistar-Imamichi rats (8-week-old females and 10-weekold males; Institute for Animal Reproduction, Ibaraki, Japan) were maintained in a temperature- and light-controlled room (12 h light:12 h darkness cycle). All animal care and surgical procedures were approved by the Institutional Animal Care Committees at Tokyo University of Pharmacy and Life Sciences (approval no: P13-67), in compliance with institutional guidelines for the care of experimental animals.

Female rats were mated with fertile or vasectomized males to induce pregnancy or pseudopregnancy (day 1 , vaginal plug) respectively. The uteri were collected from rats on days 3, 5, 7, and 9 of pregnancy. To induce artificial decidualization, $100 \mu \mathrm{l}$ of sesame oil was infused into the lumen of one uterine horn on day 5 of pseudopregnancy, when the uteri were optimally sensitized for deciduogenic stimulus. The contralateral uterine horn, which was not infused with the oil, served as a control. At $48 \mathrm{~h}$ after the intraluminal oil infusion, the rats were killed and the uterine horns (oil-infused and non-oil-infused uteri) were isolated. Delayed implantation was induced by the
}

method described previously (Tamura et al. 2003). In brief, anesthetized pregnant rats were ovariectomized on the morning of day 4 of pregnancy and received daily injections of $\mathrm{P}_{4}$ ( $3 \mathrm{mg} / \mathrm{rat}$ ) from day 4 to 10 to maintain delayed implantation. The uteri collected from $\mathrm{P}_{4}$-treated rats on day 10 of pregnancy were considered $\mathrm{P}_{4}$-primed delayed-implantation uteri. The $\mathrm{P}_{4}$-primed delayed-implanting rats were given an injection of $\mathrm{E}_{2}$ (500 ng/rat) on day 8 of pregnancy to terminate delayed implantation (induced implantation) and uteri were collected at $48 \mathrm{~h}$ after $\mathrm{E}_{2}$ treatment. To examine the effect of ovarian steroids on EPAC and RAP1 expression in the uteri, ovariectomized nonpregnant adult rats were rested for 2 weeks and given injections of $\mathrm{P}_{4}(3 \mathrm{mg} / \mathrm{rat})$ daily for 3 days and/or a single injection of $E_{2}(500 \mathrm{ng} / \mathrm{rat})$ on the third day. Rats were killed $24 \mathrm{~h}$ after $\mathrm{E}_{2}$ injection. The collected uteri were fixed in $4 \%$ paraformaldehyde, or frozen, and stored in liquid nitrogen.

\section{Immunoblotting}

Tissue lysates were prepared from the frozen uteri of pregnant or nonpregnant rats by homogenization in buffer $(50 \mathrm{mM}$ Tris$\mathrm{HCl}(\mathrm{pH}$ 7.4), $1 \mathrm{mM}$ EDTA, $150 \mathrm{mM} \mathrm{NaCl}, 1 \mu \mathrm{g} / \mathrm{ml}$ phenylmethylsulfonyl fluoride, $10 \mu \mathrm{g} / \mathrm{ml}$ aprotinin, and $1 \mu \mathrm{g} / \mathrm{ml}$ leupeptin) as described before (Yoshie et al. 2004). Cultured rat ESCs were lysed with RIPA buffer (Cell Signaling Technology). The samples were separated by SDS-PAGE and electrophoretically transferred to polyvinylidene difluoride membranes (Millipore, Billerica, MA, USA). The membranes were blocked with ImmunoBlock (DS Pharma Biomedical Co. Ltd., Osaka, Japan), and incubated with primary antibodies against Epac1 $(0.3 \mu \mathrm{g} / \mathrm{ml})$, Epac2 $(0.1 \mu \mathrm{g} / \mathrm{ml})$, or Rap1 $(0.1 \mu \mathrm{g} / \mathrm{ml})$. Immunoreactive bands were detected using $\mathrm{ECL}$ (PerkinElmer Life Science, Inc., Boston, MA, USA) after incubation with HRP-labeled goat anti-mouse or anti-rabbit $\operatorname{lgG}(0.5 \mu \mathrm{g} / \mathrm{ml}$, Vector Laboratories, Burlingame, CA, USA). The membranes were treated with stripping solution $(25 \mathrm{mM}$ glycine- $\mathrm{HCl}(\mathrm{pH} 2.0)$, containing $1 \%(\mathrm{w} / \mathrm{v}) \mathrm{SDS}$ ) and re-probed with an antibody against $\beta$-actin (clone AC-15, 1:5000, Sigma-Aldrich). The relative band intensity was assessed by densitometric analysis of digitalized autographic images using Scion image software (Scion Corp., Fredrick, MD, USA) and normalized to $\beta$-actin (Kusama et al. 2013).

\section{Immunohistochemistry and immunofluorescence}

The fixed tissues were embedded in paraffin according to standard procedures (Tamura et al. 2003). Paraffin sections were rehydrated, boiled for $20 \mathrm{~min}$ with $10 \mathrm{mM}$ citrate buffer $(\mathrm{pH}$ 6.0), and blocked with $10 \%$ normal goat serum in PBS. The tissue sections were incubated with polyclonal anti-Epac1 $(6.7 \mu \mathrm{g} / \mathrm{ml})$, anti-EPAC2 $(2 \mu \mathrm{g} / \mathrm{ml})$, anti-RAP1 $(2 \mu \mathrm{g} / \mathrm{ml})$, antip-CREB $(1: 2000)$, or anti-cyclin D3 $(30 \mu \mathrm{g} / \mathrm{ml})$ antibody. The sections were incubated with an amino acid polymer conjugated to anti-rabbit IgG Fab labeled with a HRP (Histofine Simple Stain MAX-PO MULTI, Nichirei, Tokyo, Japan), and then developed with Histofine Simple Stain DAB solution (Nichirei). The sections were counterstained with methyl green.

To study the co-localization of EPAC1, EPAC2, or RAP1 with $\mathrm{p}$-CREB in the decidua of pregnant uterus (day 9 of pregnancy), 
dual immunofluorescence was carried out as described before (Yoshie et al. 2009). Briefly, the tissue sections were incubated with primary antibodies against EPAC1, EPAC2, or RAP1 for $2 \mathrm{~h}$ and subsequently with Alexa594-conjugated goat anti-rabbit or -mouse IgG $(10 \mu \mathrm{g} / \mathrm{ml}$, Invitrogen $)$ for $1 \mathrm{~h}$. In the same preparations, the sections were incubated with the antibodies against RAP1 or p-CREB for $2 \mathrm{~h}$ and then incubated with Alexa488-conjugated goat anti-rabbit or -mouse IgG $(10 \mu \mathrm{g} / \mathrm{ml}$, Invitrogen) for $1 \mathrm{~h}$. The sections were mounted with anti-fading reagent (SlowFade; Invitrogen) and examined under a microscope (Axiovert 200M; Zeiss, Jena, Germany).

\section{RAP1 GTPase activation assay}

The amount of active RAP1 was determined using the RAP1 activation assay kit (Millipore) as described previously (Kusama et al. 2013). Decidua at implantation site (IS) and uterine endometrium at inter-IS were dissected on day 9 of pregnancy. The tissues were homogenized in lysis buffer $(50 \mathrm{mM}$ Tris- $\mathrm{HCl}$ (pH 7.4), 0.5 M NaCl, $1 \%$ NP40, $2.5 \mathrm{mM} \mathrm{MgCl}_{2}$, and $5 \%$ glycerol). The lysates were incubated with a GST-RalGDSRAP1-binding domain fusion protein and pulled down with glutathione agarose. The proteins were separated by SDSPAGE and immunoblotted using an anti-RAP1 antibody.

\section{Primary culture of uterine stromal cells}

Non-pregnant uteri were isolated from surrounding fat tissues, dissected open longitudinally, and cut into small pieces. Uterine pieces were washed thoroughly with $\mathrm{Ca}^{2+} / \mathrm{Mg}^{2+}$ free Hank's balanced salt solution (HBSS) supplemented with $100 \mu \mathrm{g} / \mathrm{ml}$ penicillin, $100 \mu \mathrm{g} / \mathrm{ml}$ streptomycin, $200 \mu \mathrm{g} / \mathrm{ml}$ neomycin, and $0.5 \mu \mathrm{g} / \mathrm{ml}$ amphotericin B. The tissues were digested with dispase $(6 \mathrm{mg} / \mathrm{ml}$, Gibco $)$ and pancreatin $\left(25 \mathrm{mg} / \mathrm{ml}\right.$, Sigma-Aldrich) for $1 \mathrm{~h}$ at $4{ }^{\circ} \mathrm{C}, 1 \mathrm{~h}$ at room temperature, and then $10 \mathrm{~min}$ at $37^{\circ} \mathrm{C}$. After adding HBSS, containing $10 \%$ charcoal-stripped (CS) fetal bovine serum (FBS), the enzyme-digested suspension was gently pipetted to release the sheet of luminal epithelial cells. The remaining tissues were digested with type I collagenase $(0.5 \mathrm{mg} / \mathrm{ml}$, Sigma-Aldrich) at $37^{\circ} \mathrm{C}$ for $30 \mathrm{~min}$, and the digested suspension was passed through a $70 \mu \mathrm{m}$ nylon strainer to remove undigested tissues and epithelial cells. The cells were resuspended in phenol red-free DMEM and Ham's F-12 (1:1) supplemented with $10 \%$ CS-FBS, antibiotics and antimycotics, and seeded onto culture dishes. After an initial incubation for $1 \mathrm{~h}$, the medium was replaced with a fresh medium to remove free-floating cells. In vitro decidualization was induced by treatment with $100 \mathrm{nM}$ MPA plus $500 \mu \mathrm{M}$ db-cAMP, or $200 \mu \mathrm{M}$ Phe and/or $200 \mu \mathrm{M}$ CPT for $48 \mathrm{~h}$.

\section{Treatment with siRNA}

ESCs grown to $50 \%$ confluency in 24-well plates were transfected with a nontargeting control siRNA (30 pmol/well, Qiagen), Epac1 siRNA (30 pmol/well; 5'-AUUGAGAUUCUUCUGCUCCUUGAGG-3', 5'-CCUCAAGGAGCAGAAGAAUCUCAAU-3', Invitrogen), Epac2 siRNA (30 pmol/well;
5'-UGUUCUUUAAGUCUGACUGUAUUCG-3', 5'-CGAAUACAGUCAGACUUAAAGAACA-3', Invitrogen), or Rap1 siRNA (30 pmol/well; 5'-CUGCAAAGUCAAAGAUCAA-3', Santa Cruz Biotechnology) using Lipofectamine RNAiMAX transfection reagent (Invitrogen) according to the manufacturer's instructions. After treatment with siRNA for $24 \mathrm{~h}$, the medium was removed and the cells were cultured in fresh medium for $24 \mathrm{~h}$. Concentrations of siRNA sufficient to knockdown the expression of each protein were predetermined (Kusama et al. 2013).

\section{RNA extraction and real-time RT-PCR}

Total RNA was extracted using Isogen (Nippon Gene, Tokyo Japan) according to the manufacturer's instructions. RNA (100 ng) was amplified by real-time RT-PCR using the iScript One-Step RT-PCR Kit with SYBR Green (Bio-Rad Laboratories). The sense (S) and antisense (AS) primers were $5^{\prime}$-CATGCTTTCTCACTACATCCAT-3' (S) and 5'-CTTCAGGAGTAGCTAGGGAAGA-3' (AS) for Prl; 5'-ATCCAGCGAGCTGAAGTCAT-3' (S) and $5^{\prime}$-ATGCCTATACATGCGTGCAA-3' (AS) for Prl8a2; and 5'-AAAGCTGTGGCGTGATGG-3' (S) and 5'-TTCAGCTCTGGGATGACCTT-3' (AS) for Gapdh. The fold change in the expression of each gene was calculated using the $\Delta \Delta C t$ method with Gapdh as an internal control (Kusama et al. 2013).

\section{Statistical analysis}

Data were expressed as the mean \pm s.E.M. Significance was assessed using the Tukey-Kramer multiple comparisons test. A $P$ value $<0.05$ was considered statistically significant.

\section{Results}

\section{Expression of EPAC1, EPAC2, and RAP1 in the peri-implantation uterus}

We examined the spatiotemporal expression of EPAC1, EPAC2, and RAP1 protein in the uterus during periimplantation period through the use of immunoblotting and immunohistochemistry. EPAC2 and RAP1 expressed from day 3 and their levels were increased on day 7 and sustained on day 9 (Fig. 1A). EPAC1 was also expressed from day 3 of pregnancy and its level was increased on day 7. We next examined the spatiotemporal expression of EPAC1, EPAC2, and RAP1 by immunohistochemistry. Although EPAC1 was low to undetectable in days 3 and 5 pregnant uteri, its was detected at low level in decidual cells on days 7 and 9 of pregnancy (Fig. 1B). EPAC2 was expressed in the glandular and luminal epithelium and the stroma adjacent to luminal epithelium on days 3 and 5 of pregnancy, and the level was increased in decidual cells on days 7 and 9 (Fig. 1B). RAP1 was mainly detected in the luminal and glandular epithelium on days 3 and 5, and was highly expressed in the decidual cells on days 7 and 9 (Fig. 1B). The signal of EPAC1 was weaker than that of EPAC2 or RAP1. Furthermore, dual 
A
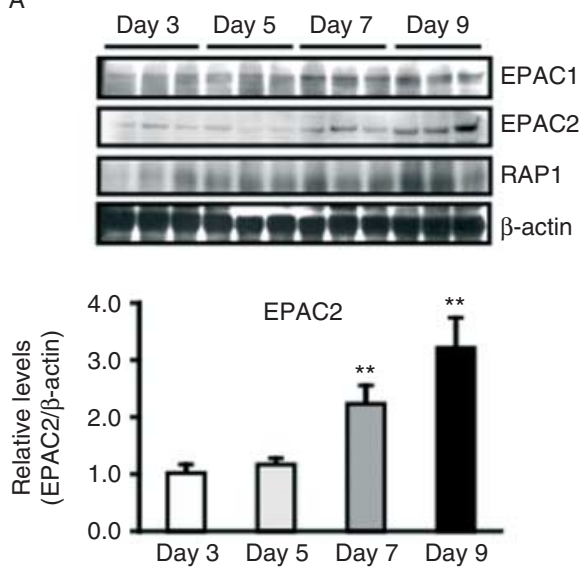

B
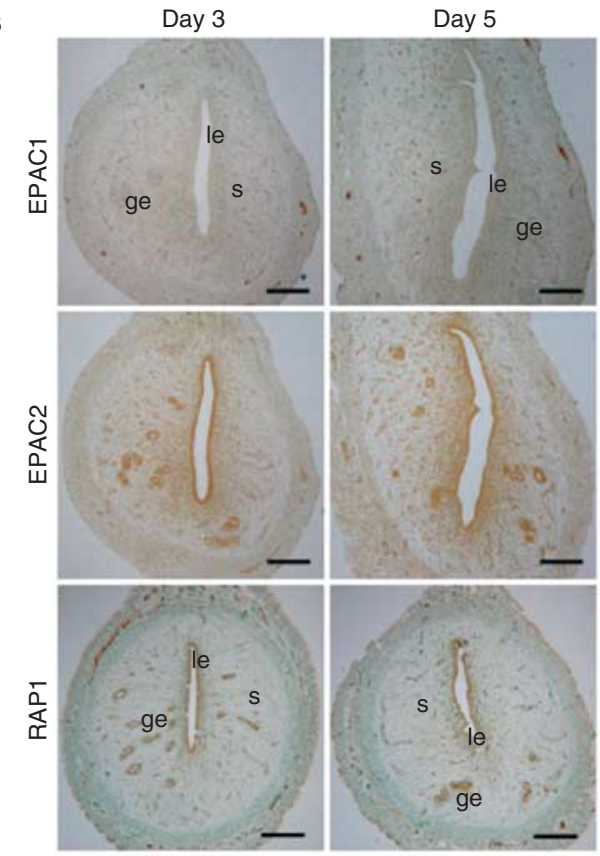

C

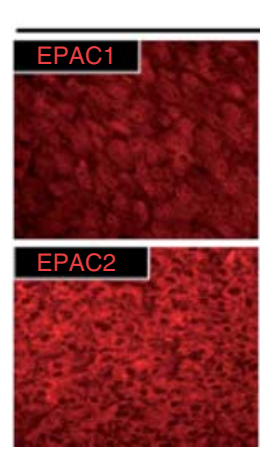

Day 9 (decidua)
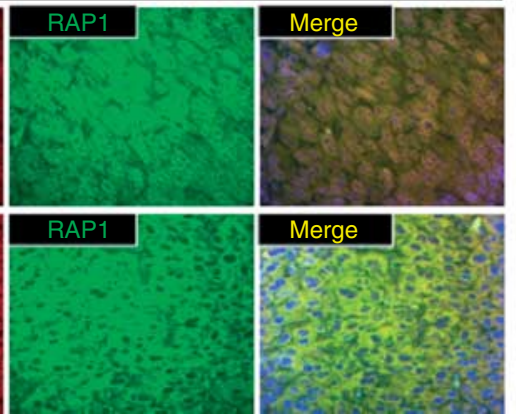
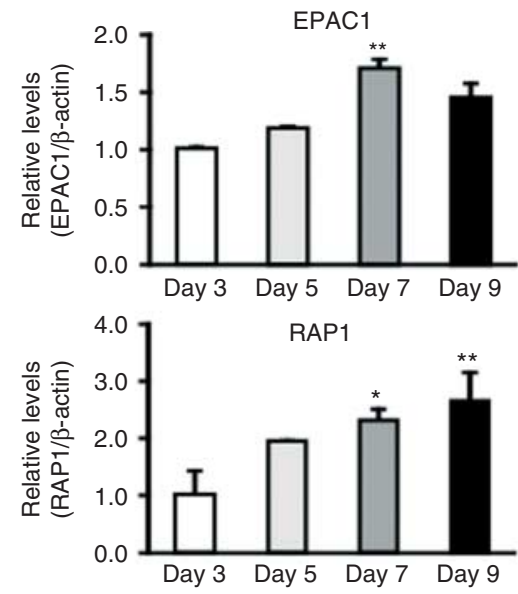

Day 7
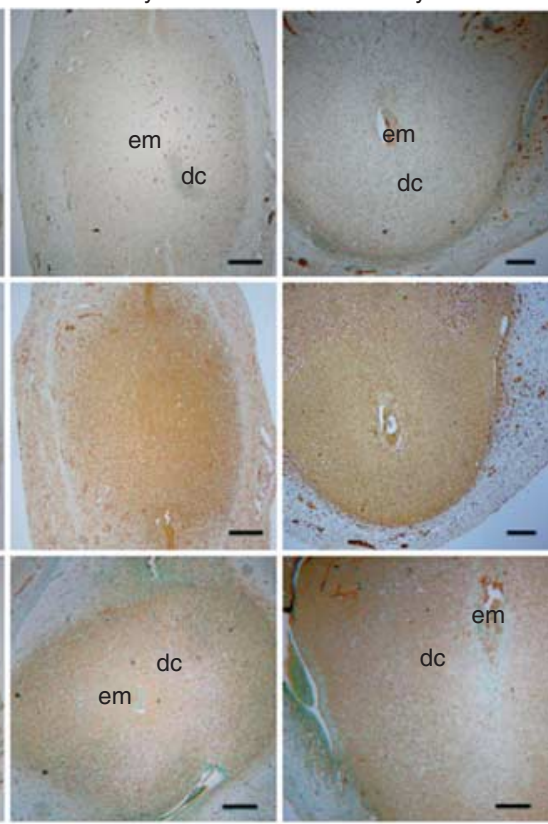

D

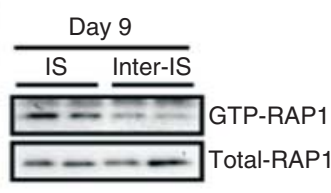

Figure 1 Expression of EPAC1, EPAC2, and RAP1 in the peri-implantation uterus. (A) Uterine samples (30 $\mu$ g protein) were subjected to immunoblot analysis using antiEPAC1, EPAC2, RAP1, or $\beta$-actin antibodies. The graphs show the relative levels of EPAC1, EPAC2, and RAP1 normalized to $\beta$-actin levels from three independent experiments. ${ }^{*} P<0.05,{ }^{* *} P<0.01$ vs day 3 .

(B) Immunostaining of EPAC1, EPAC2, and RAP1 was carried out on uterine cross sections taken at days 3, 5, 7, and 9 of pregnancy. The sections were counterstained with methyl green to show nuclei. le, luminal epithelial cells; ge, glandular epithelial cells; s, stromal cells; dc, decidual cells. Scale bars $=250 \mu \mathrm{m}$. (C) Dual immunofluorescence analysis of EPAC $1 / 2$ and RAP1 was carried out on uterine sections taken at day 9 of pregnancy. (D) Implantation site (IS) and inter-IS dissected from day 9 pregnant uteri were assayed by a pull-down to determine GTP-RAP1 levels. The panels show representative immunoblots of GTP-RAP1 and total RAP1.

immunofluorescence analysis revealed that both EPAC1 and EPAC2 were Co-localized with RAP1 in decidual cells at IS on day 9 of pregnant uterus (Fig. 1C). It should be noted that RAP1 was activated in the decidua at the IS, and active RAP1 (GTP-RAP1) level was much higher at IS than inter-IS.

\section{Expression of EPAC1, EPAC2, and RAP1 in the delayed-implantation model}

A delayed-implantation model was used to examine whether uterine expression of EPAC1, EPAC2, and RAP1 was regulated by ovarian hormones during the peri-implantation period (Fig. 2). Although low levels 


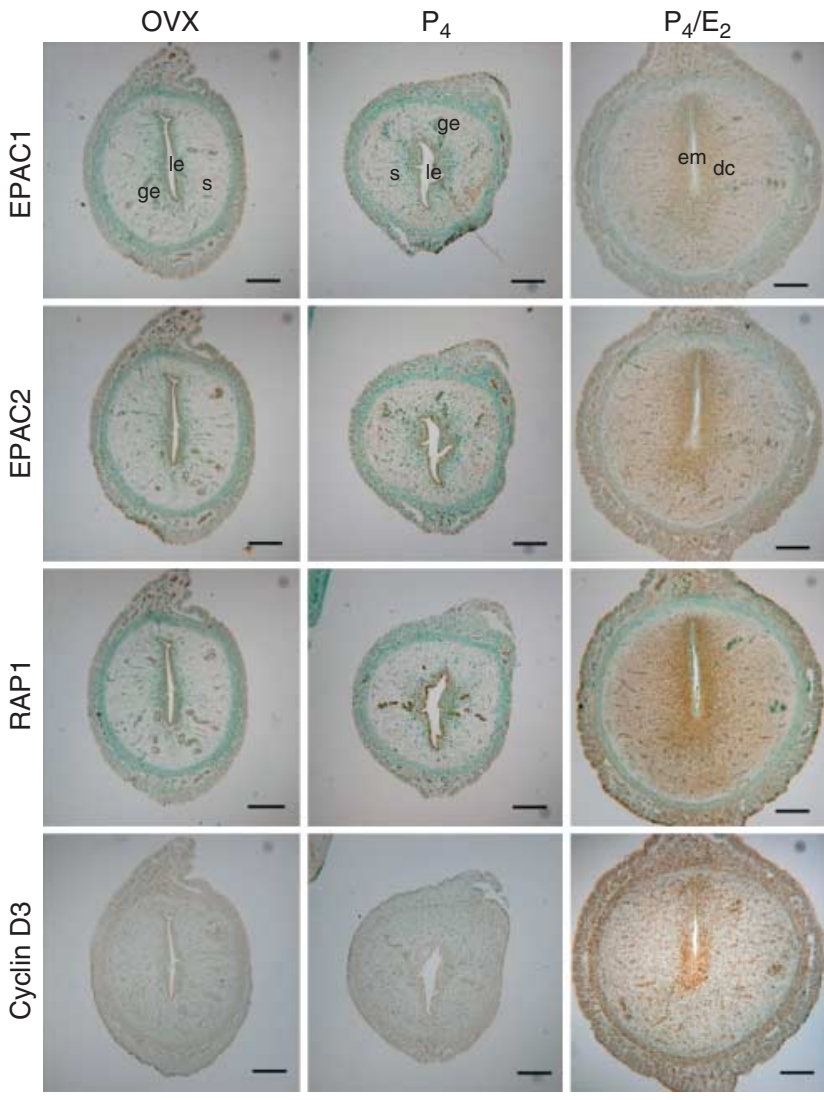

Figure 2 Expression of EPAC1, EPAC2, and RAP1 in the delayedimplantation model. Pregnant rats were ovariectomized on day 4 and injected with $\mathrm{P}_{4}(3 \mathrm{mg} / \mathrm{rat})$ or vehicle daily from days 4 to 9 of pregnancy. To initiate implantation in $\mathrm{P}_{4}$-primed delayed-implanting rats, $E_{2}$ (500 ng/day per rat) was injected on day 8 . Immunostaining of EPAC1, EPAC2, RAP1 or cyclin D3 was carried out on uterine sections on day 10 of ovariectomized (control), $\mathrm{P}_{4}$-treated, or delayedimplantation $\left(\mathrm{P}_{4} / \mathrm{E}_{2}\right)$ rats. The sections were counterstained with methyl green to show nuclei. le, luminal epithelial cells; ge, glandular epithelial cells; s, stromal cells; dc, decidual cells. Scale bars $=250 \mu \mathrm{m}$.

of EPAC1, EPAC2, and RAP1 expression were observed in endometrial luminal and glandular cells in ovariectomized control and $\mathrm{P}_{4}$-primed rats, their expressions were augmented in decidual cells when the implantation process was resumed by injecting $E_{2}$ in $P_{4}$-primed rats (Fig. 2). Upregulation of cyclin D3 expression, a marker of decidual cells in the $\mathrm{P}_{4} / \mathrm{E}_{2}$ group, indicated that the delayed-implantation model in the study was in accordance with the previous report (Das et al. 1999).

\section{Effect of ovarian steroids on the uterine expression of EPAC1, EPAC2, and RAP1}

The enhanced expression of EPAC1, EPAC2, and RAP1 in uterine in response to $E_{2}$ in the delayed-implanting rats led us to examine the direct effects of ovarian steroids on these expressions. To assess the effects of ovarian steroids on EPAC1, EPAC2, or RAP1 expression, nonpregnant rats were ovariectomized and treated with $E_{2}$ and/or $P_{4}$. Any effects of $E_{2}$ and/or $P_{4}$ on the expression of EPAC1, EPAC2, or RAP1 were minor and not statistically significant (Fig. 3).

\section{Expression of EPAC1, EPAC2, and RAP1 in artificially induced deciduoma}

To explore the expression of EPAC1, EPAC2, and RAP1 during decidualization, the uteri of pseudopregnant rats were prepared. Injection of sesame oil to induce decidualization increased EPAC2 and RAP1 expression at the decidual zone compared with the intact group, whereas the same treatment only slightly stimulated EPAC1 expression (Fig. 4A). In addition, cyclin D3 expression was also increased at the decidual zone in the oil-treated group (Fig. 4A). Similar changes in these expressions were observed in immunoblot analyses (Fig. 4B, C and D). These observations were similar to what we observed in the uteri during pregnancy.

\section{Activation of cAMP/PKA signaling during decidualization in rat}

It has been reported that CAMP concentrations are elevated at the IS in rats (Vilar-Rojas et al. 1982). An in vitro study demonstrated that prostaglandin $\mathrm{E}_{2}\left(\mathrm{PGE}_{2}\right)$ increases intracellular cAMP levels and activates PKA in rat ESCs (Yee \& Kennedy 1993). However, it has not been demonstrated whether cAMP signaling is activated in decidual cells at the IS. We next examined the phosphorylation of cAMP-responsive element-binding protein (p-CREB), which is a central mediator of PKA activity, as an
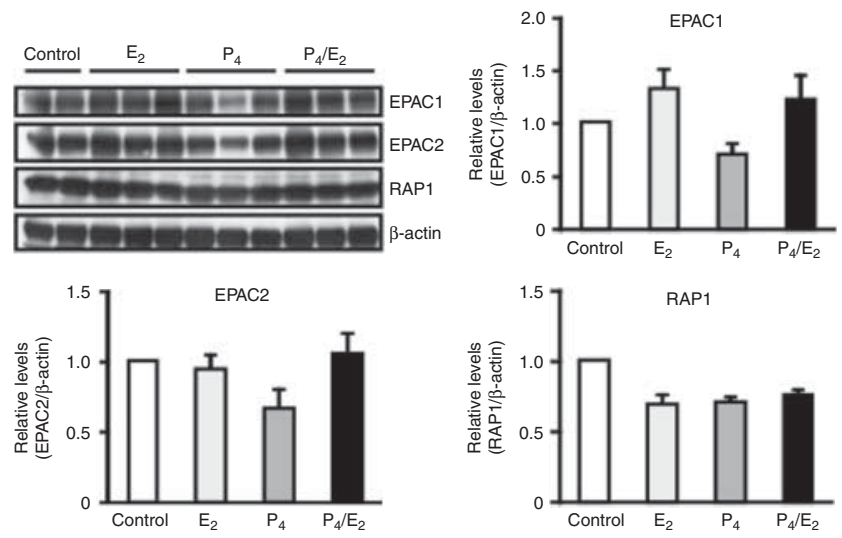

Figure 3 Effect of ovarian steroids on the uterine expression of EPAC1, EPAC2, and RAP1. Ovariectomized rats were given injections of $\mathrm{P}_{4}$ ( $3 \mathrm{mg} / \mathrm{rat}$ ) daily for 3 days and/or a single injection of $E_{2}$ (500 ng/rat) on the third day. Rats were killed $24 \mathrm{~h}$ after $\mathrm{E}_{2}$ injection. Uterine lysates (30 $\mu$ g protein) were subjected to immunoblot analysis using anti-EPAC1, EPAC2, RAP1, or $\beta$-actin antibodies. The lower graphs show the relative levels of expression normalized to $\beta$-actin levels from three independent experiments. 
index of CAMP activation in the rat uterus. Immunohistochemical analysis showed that low level of p-CREB was localized to the nuclei of glandular and luminal epithelial cells on days 3 and 5 of pregnancy (Fig. 5A-a and b). On days 7 and 9 of pregnancy, intense staining of p-CREB was detected in the nuclei of decidual cells (Fig. 5A-c, d, e and $\mathrm{f}$ ). In the delayed-implantation model, $E_{2}$ priming with $\mathrm{P}_{4}$-treated uteri expressed $p$-CREB in decidual cells, while ovariectomized control or $\mathrm{P}_{4}$ priming uteri slightly expressed $p$-CREB in the luminal and glandular epithelium (Fig. 5B). Furthermore, in artificial decidualization, induced by the sesame oil infusion, $p$-CREB was increased at the decidual zone compared with the intact group (Fig. 5C). Collectively, these findings indicated that cAMP signaling was activated during decidualization in the rat uterus. Furthermore, we confirmed that EPAC1, EPAC2, or RAP1 was expressed in p-CREB-immunoreactive decidual cells at day 9 of pregnant uterus (Fig. 5D).

\section{Effects of EPAC1, EPAC2, and RAP1 in an in vitro rat decidualization model}

The close association of EPAC and RAP1 expression with decidualization prompted us to examine the functional roles of these factors using an in vitro rat decidualization model. As previously reported, treatment with MPA and $\mathrm{db}$-cAMP increased the expression of the decidual markers Prl (Soares 2004) and Prl8a2 (Roby et al. 1993)
A
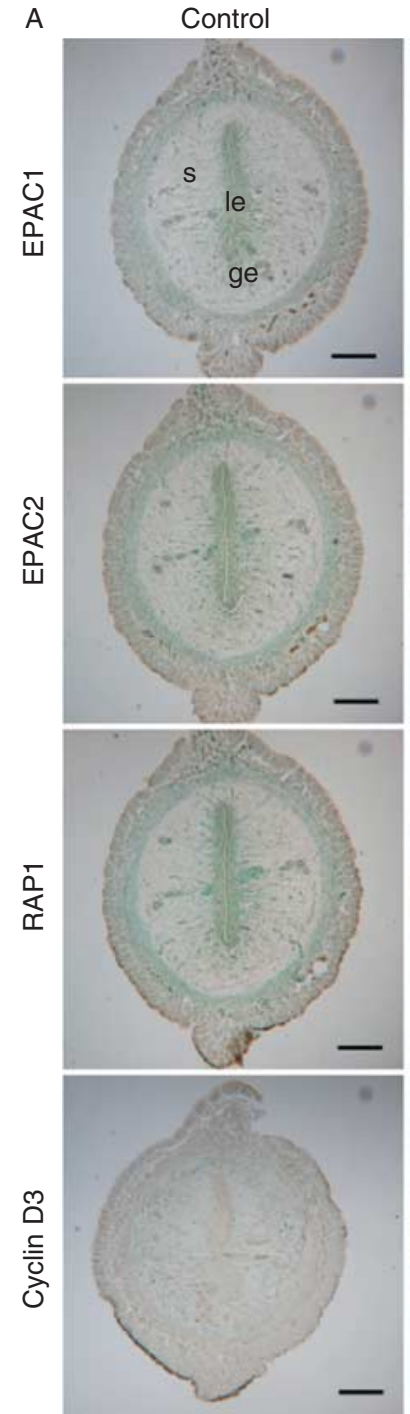

Oil
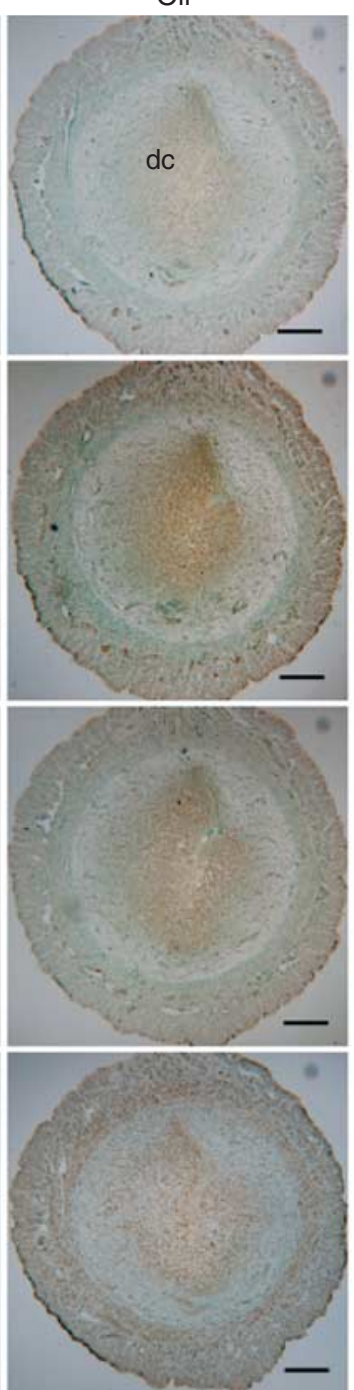

B
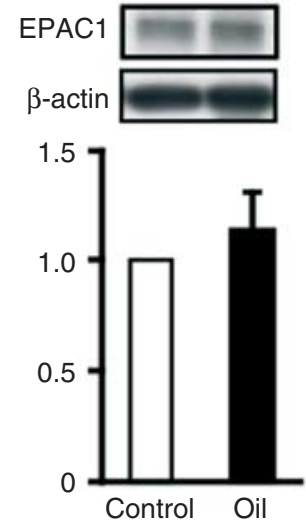

D
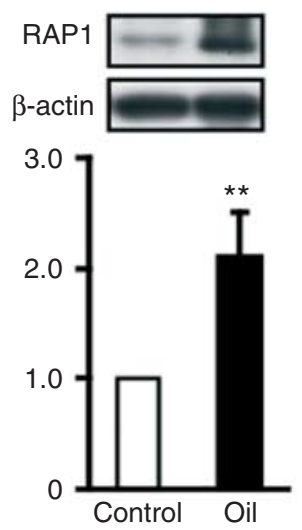

C
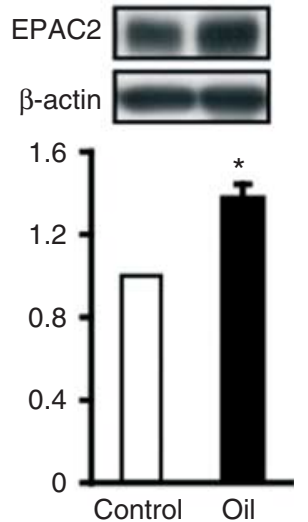

Figure 4 Expression of EPAC1, EPAC2, and RAP1 in artificially induced deciduoma. (A) Female rats were mated with vasectomized males and $100 \mu$ l of sesame oil was infused into the lumen of one uterine horn on day 5 . The uteri were dissected at $48 \mathrm{~h}$ after oil infusion. Immunostaining of EPAC1, EPAC2, RAP1, or cyclin D3 was carried out on uterine sections taken from the pseudopregnant rats. The sections were counterstained with methyl green to show nuclei. le, luminal epithelial cells; ge, glandular epithelial cells; s, stromal cells; dc, decidual cells. Scale bars $=250 \mu \mathrm{m}$. (B, C and D). Uterine samples (30 $\mu \mathrm{g}$ protein) were subjected to immunoblot analysis using anti-EPAC1 (B), EPAC2 (C), RAP1 (D), or $\beta$-actin antibodies. The lower graphs show the relative levels of expression normalized to $\beta$-actin levels from three independent experiments. ${ }^{*} P<0.05, * * P<0.01$ vs control. 
(Fig. 6A). Furthermore, we evaluated the effects of PKA- and EPAC-selective cAMP analogs on Prl and Prl8a2 expression. A PKA-selective cAMP analog (Phe), but not an EPAC-selective CAMP analog (CPT), increased

A

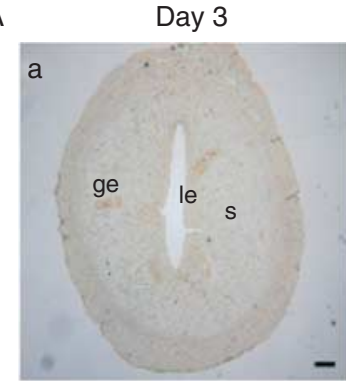

Day 7
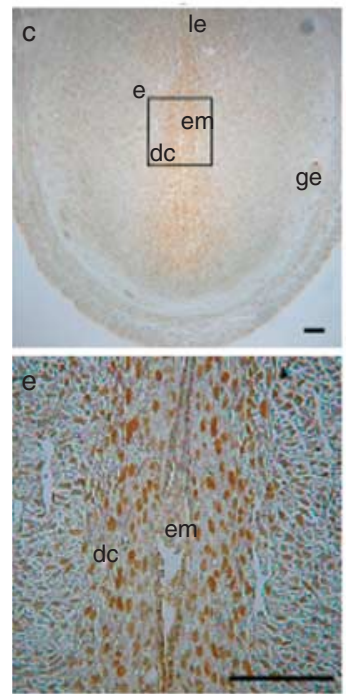

$-$

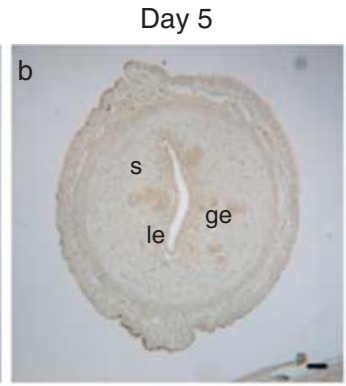

Day 9
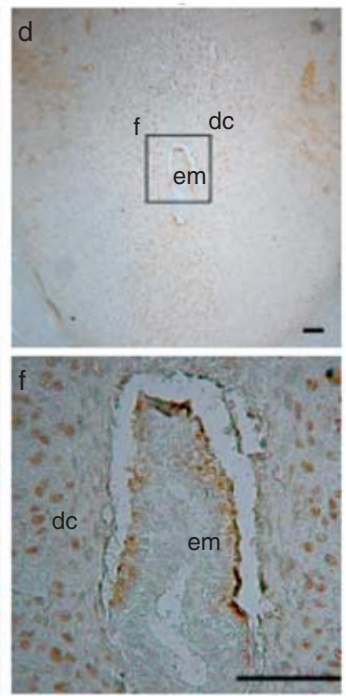

D

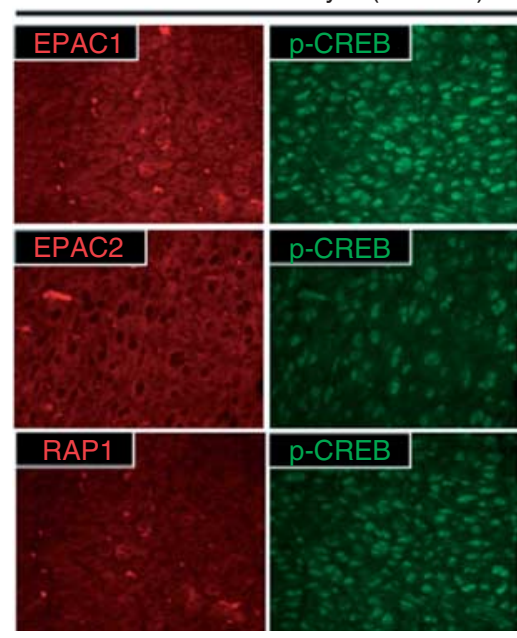

Prl or Prl8a2 mRNA expression (Fig. 6B). It should be noted that siRNA-mediated silencing of EPAC1, EPAC2, or RAP1 significantly inhibited MPA plus db-cAMPinduced Prl or Prl8a2 mRNA expression (Fig. 6C and D).

B

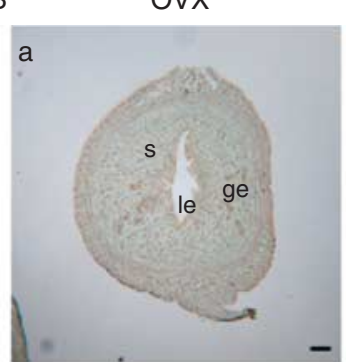

$\mathrm{P}_{4} / \mathrm{E}_{2}$
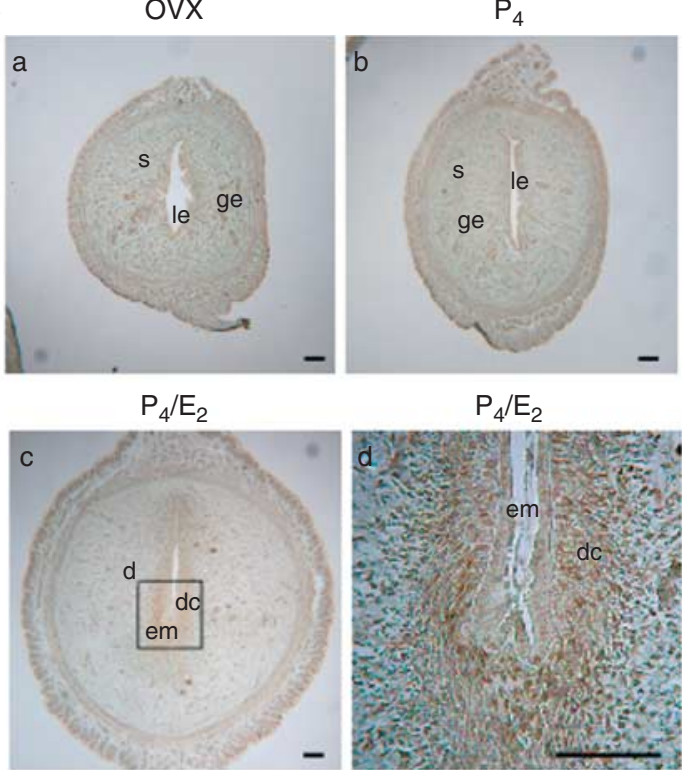

$\mathrm{P}_{4} / \mathrm{E}_{2}$

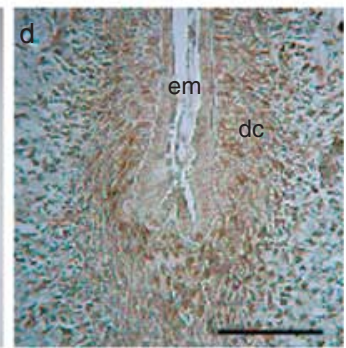

C
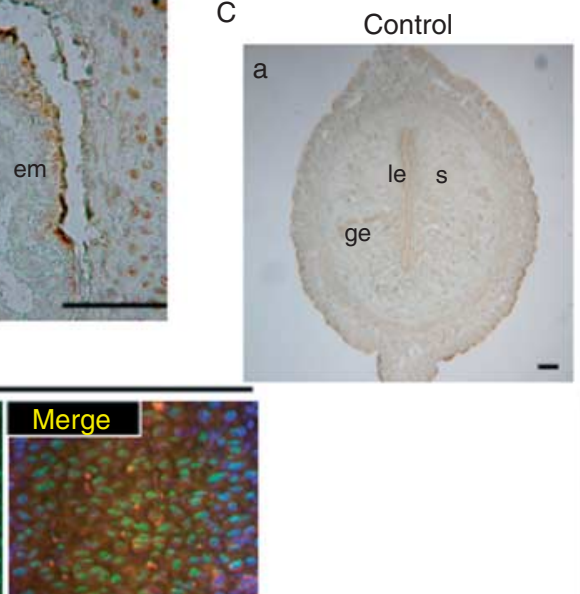

$-$

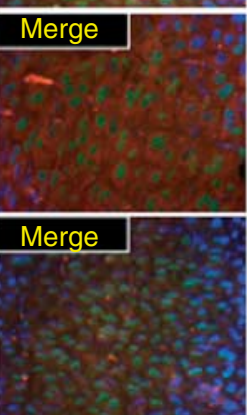

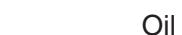

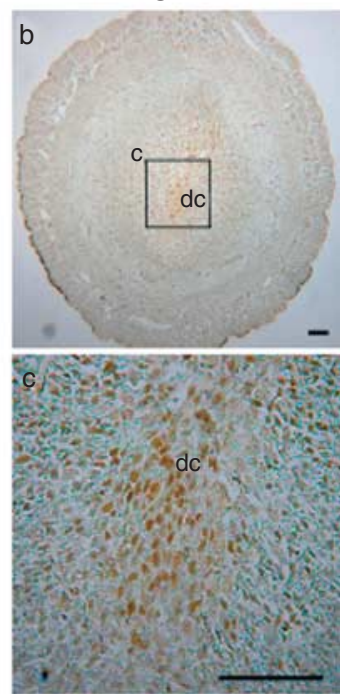

Figure 5 Activation of cAMP/PKA signaling during decidualization in rat. (A) Localization of p-CREB in the peri-implantation uterus. Immunostaining of p-CREB was carried out on uterine sections taken at days 3 (a), 5 (b), 7 (c), and 9 (d) of pregnancy. (e and f) Magnified pictures of (c and d) (B) localization of p-CREB in uterine sections taken from ovariectomized (OVX; a), $P_{4}$-treated (b), and $P_{4} / E_{2}(c$ and d)-treated rats. (d) Magnified pictures of (c). (C) Localization of p-CREB in artificially induced deciduoma. Control (a) and oil infused (b and c) uterus were subjected to immunostaining for p-CREB. (c) Magnified pictures of (b). Sections were counterstained with methyl green to show nuclei. le, luminal epithelial cells; ge, glandular epithelial cells; s, stromal cells; dc, decidual cells; em, embryo. Scale bars $=100 \mu \mathrm{m}$. (D) Dual immunofluorescence analysis of EPAC1/2, RAP1, and $\mathrm{p}$-CREB was carried out on uterine sections taken at day 9 of pregnancy. 


\section{Discussion}

In the present study, we analyzed the spatiotemporal expression of EPAC1, EPAC2, and RAP1 in rat uteri under several models of pregnancy such as peri-implantation of normal pregnancy, delayed-implantation model, and artificial decidualization, and found that EPAC1, EPAC2, and RAP1 played their roles in decidualization. We have previously shown that EPAC1 and EPAC2 are expressed in the endometrial epithelium and stroma throughout the menstrual cycle in women (Kusama et al. 2013). Although EPAC1, EPAC2, and RAP1 were expressed in endometrial glandular, luminal epithelial, and stromal cells on days 3 and 5 of pregnancy in rats, their expression was significantly increased in decidual cells after embryo implantation. Elevation of these expressions in decidual cells concomitant with initiation of decidualization followed by $\mathrm{E}_{2}$-induced implantation indicates that their expression is associated with
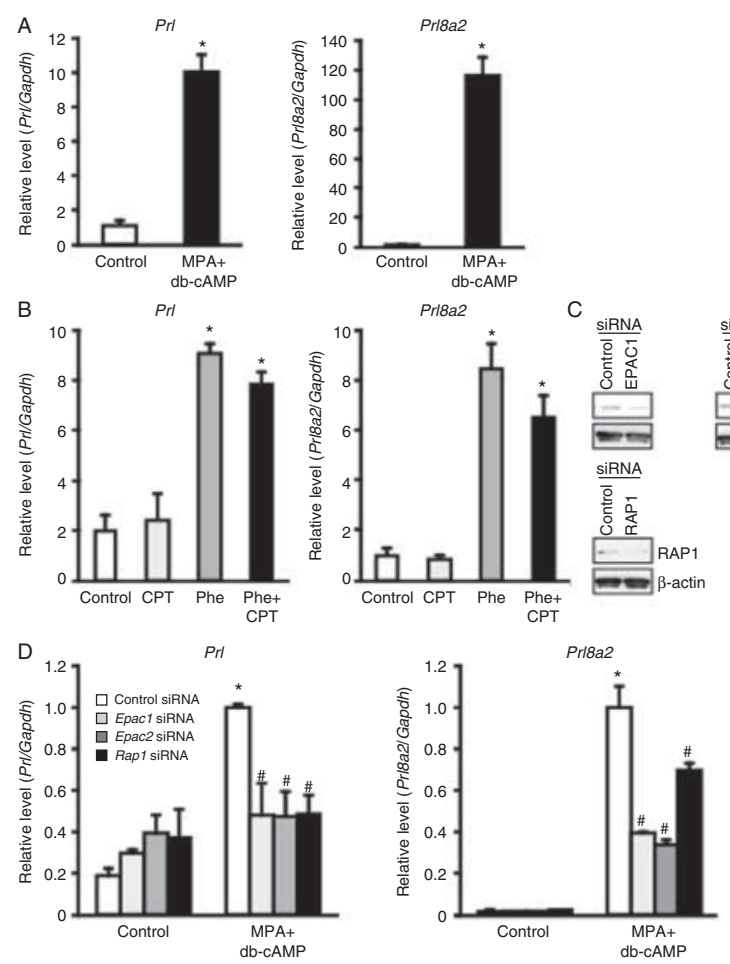

Figure 6 Effects of EPAC1, EPAC2, or RAP1 knockdown on an in vitro decidualization. (A and B) Rat ESCs were treated for $48 \mathrm{~h}$ with MPA (100 nM) and db-cAMP (500 $\mu \mathrm{M})(\mathrm{A})$, or CPTand/or Phe (B). Total RNA was isolated and subjected to real-time RT-PCR analysis to determine Prl and Prl8a2 mRNA levels. Gapdh was used as an internal control. (C and D) ESCs were treated for $24 \mathrm{~h}$ with nontargeting control (Cont), Epac1, Epac2, or Rap1 siRNA, and cultured for an additional $24 \mathrm{~h}$. ESCs were then treated with MPA and db-cAMP for $48 \mathrm{~h}$. The expression of EPAC1, EPAC2, or RAP1 was determined by immunoblotting $(C)$. The same blot was stripped and re-probed with an anti- $\beta$-actin antibody as a loading control. Total RNA was subjected to real-time RT-PCR analysis to determine Prl and Prl8a2 mRNA levels (D). Gapdh was used as an internal control. The data from three independent experiments are presented. ${ }^{*} P<0.01$ vs Cont, ${ }^{\sharp} P<0.01$ vs Cont siRNA. Values represent the mean \pm s.E.M. decidualization. Embryonic development, implantation, and decidualization are strictly regulated by the coordinated effects of $\mathrm{P}_{4}$ and $\mathrm{E}_{2}$. In rodents, circulating $\mathrm{P}_{4}$ concentrations were elevated from day 1 to day 4 of pregnancy (Cross et al. 1994, Carson et al. 2000). However, treatment with $\mathrm{P}_{4}$ or $\mathrm{P}_{4}$ plus $\mathrm{E}_{2}$ did not affect EPAC1, EPAC2, and RAP1 expression in the uterus of ovariectomized nonpregnant rats. In addition, changes in EPAC1, EPAC2, and RAP1 expressions were not observed in the rat uteri during estrous cycle (data not shown). Thus, ovarian steroids are unlikely to directly contribute to the upregulation of EPAC1, EPAC2, or RAP1 expression in ESCs, although ovarian steroids are indispensable for implantation and decidualization. Furthermore, even in the absence of the blastocyst, significant upregulation of EPAC2 and RAP1 was mimicked by artificially induced decidualization in pseudopregnant rats. Therefore, the induction of EPAC2 and RAP1 is not dependent on ovarian hormones, rather these inductions could be associated with implantationrelated stimuli. However, it remains to be established how EPAC and RAP1 expression is positively regulated during decidualization in rats.

Accumulation of CAMP at the IS has been reported in rats (Vilar-Rojas et al. 1982). In the present study, we observed intense $p$-CREB staining in decidual cells in the pregnant uterus, in the $E_{2}$-stimulated uterus in a delayedimplantation model, and in artificially induced deciduoma in pseudopregnant rats. These results imply that PKA-mediated CAMP signaling is activated in decidual cells at the IS. It should be noted that knockdown of EPAC1, EPAC2, or RAP1 inhibited MPA plus db-cAMPinduced expression of $\mathrm{Prl}$ and Prl8a2, well-recognized decidual markers in rat ESCs. Thus, results from those studies revealed that EPAC and RAP1 play key roles in decidualization in rats. By contrast, treatment with MPA plus db-cAMP or PKA-selective cAMP analog (Phe), but not with Epac-selective cAMP analog (CPT), induced $\mathrm{Prl}$ and $\mathrm{Pr} / 8 \mathrm{a} 2$ expression, indicating the predominant roles of PKA-mediated cAMP signaling in decidualization in rats. We previously reported that CPT enhanced Phe- or ovarian steroid-induced IGFBP1 and PRL expression in human ESCs (Kusama et al. 2013, 2014). Furthermore, knockdown of EPAC1, EPAC2, or RAP1 inhibited either Phe- or ovarian steroid-induced IGFBP1 and PRL expression. These findings indicate that EPAC/Rap1 is involved in PKA-mediated cAMP signaling, and that both PKA and EPAC signaling coordinately regulate decidualization in human ESCs (Kusama et al. 2013). Several studies have revealed that PKA and EPAC are synergistically activated in the cAMP signaling pathway in other system. Radixin functions as a scaffolding protein that assembles EPAC and PKA into a functional compartment, thus facilitating CAMP-mediated signaling and RAP1 activation (Hochbaum et al. 2011). Although the role of radixin in the decidua has not been determined, it is abundantly expressed in uterine stromal cells surrounding 
the implanting embryo in mice (Matsumoto et al. 2006). The co-operative action of PKA and EPAC in CAMP signaling is crucial for the differentiation of 3T3-L1 fibroblast to adipocytes (Petersen et al. 2008). Therefore, it is conceivable that EPAC and RAP1 affect PKAmediated CAMP signaling in rat ESCs, as has been observed in human ESCs (Kusama et al. 2013). Further study is needed to clarify the synergistic regulation of PKA and EPAC in CAMP-induced decidualization.

In rodents and humans, $\mathrm{PGE}_{2}$ is a crucial factor that regulates decidualization (Kennedy 1983, Frank et al. 1994). An in vitro study demonstrated that treatment with $\mathrm{PGE}_{2}$ elevates intracellular cAMP levels and promotes decidualization via the activation of PKA in rat ESCs (Yee \& Kennedy 1993). There are four G-protein-coupled receptors that respond to $\mathrm{PGE}_{2}$ : EP1, EP2, EP3, and EP4. EP2 and EP4, which are coupled to adenylyl cyclase activation, and EP3, which is coupled to inhibition of adenylyl cyclase, are expressed in the rat uterus (Sugimoto \& Narumiya 2007). EP2 and EP3 in the endometrium increased to the maximum levels on day 5 of pregnancy. EP4 was exclusively expressed in the endometrial stroma. It has been reported that $\mathrm{PGE}_{2}$ promotes decidualization via EP3 and EP4 in rat ESCs (Papay \& Kennedy 2000). Furthermore, mouse ESCs differentiated into decidualized cells in response to elevated cAMP levels, which is mediated by $\mathrm{PGE}_{2}$ via EP2 (Pakrasi \& Jain 2008). Thus, activation of cAMP signaling is crucial for decidualization in rodents and humans.

It has been demonstrated that CCAAT/enhancerbinding protein $\beta$ (CEBPB)-deficient mice are infertile (Sterneck et al. 1997, Wang et al. 2012), and that $\mathrm{PGE}_{2} /$ EP4-mediated cAMP signaling activates both PKA and EPAC pathways, and then phosphorylates CEBPB, a basic leucine zipper family transcriptional factor, to promote the expression of the IL23 subunit p19 in bone marrow-derived dendritic cells (Kocieda et al. 2012). The expression of the CEBPB is upregulated by EPAC/ RAP1 signaling in human umbilical vein endothelial cells and mouse fibroblast cells (Yarwood et al. 2008, Borland et al. 2009). In our observation, an EPAC agonist was able to stimulate the DNA-binding activity of CEBPB for PRL expression in human ESCs, (K Kusama, unpublished data). In addition, Mantena et al. (2006) demonstrated that the expression of CEBPB is increased by $\mathrm{P}_{4}$ and $E_{2}$, which induces implantation in delayedimplantation model mice. CEBPB expression, regulated by $\mathrm{P}_{4}$ and $\mathrm{E}_{2}$, also controls the proliferation or decidualization of ESCs (Mantena et al. 2006). Furthermore, knockdown of CEBPB was shown to prevent decidualization of human ESCs (Wang et al. 2012). Together with the data from this study, it is possible that EPAC and RAP1 expressions mediate decidualization via modulating expression or activity of CEBPB in rat and human ESCs. Further studies are required to confirm the mechanism by which Epac regulates PKA-induced expression of decidual markers.

In conclusion, we demonstrate in this study the spatiotemporal expression patterns of EPAC1, EPAC2, and RAP1 in the rat uterus during the peri-implantation period and show that the expression of these factors in stromal cells is closely associated with decidualization. In addition, our in vitro studies revealed that EPAC and RAP1 are crucial for CAMP/PKA-mediated decidualization in rats.

\section{Declaration of interest}

The authors declare that there is no conflict of interest that could be perceived as prejudicing the impartiality of the research reported.

\section{Funding}

This work was supported by a Grant-in-Aid for Young Scientists (B) 25861511 (to M Yoshie) from the Japan Society for the Promotion of Science (JSPS).

\section{Acknowledgements}

The authors are grateful to Dr Kazuhiko Imakawa (The University of Tokyo) for insightful comments and for editing the manuscript.

\section{References}

Ahn YH, Han JH \& Hong SH 2006 Rap1 and p38 MAPK mediate 8-chlorocAMP-induced growth inhibition in mouse fibroblast DT cells. Journal of Cellular Physiology 209 1039-1045. (doi:10.1002/jcp.20821)

Borland G, Bird RJ, Palmer TM \& Yarwood SJ 2009 Activation of protein kinase $\mathrm{C} \alpha$ by EPAC1 is required for the ERK- and CCAAT/enhancerbinding protein $\beta$-dependent induction of the SOCS-3 gene by cyclic AMP in COS1 cells. Journal of Biological Chemistry 284 17391-17403. (doi:10.1074/jbc.M109.015370)

Bos JL 2006 Epac proteins: multi-purpose cAMP targets. Trends in Biochemical Sciences 31 680-686. (doi:10.1016/j.tibs.2006.10.002)

Carson DD, Bagchi I, Dey SK, Enders AC, Fazlebas AT, Lessey BA \& Yoshinaga K 2000 Embryo implantation. Developmental Biology 223 217-237. (doi:10.1006/dbio.2000.9767)

Cross JC, Werb Z \& Fisher SJ 1994 Implantation and the placenta: key pieces of the developmental puzzle. Science 266 1508-1518. (doi:10. 1126/science.7985020)

Das SK, Lim H, Paria BC \& Dey SK 1999 Cyclin D3 in the mouse uterus is associated with the decidualization process during early pregnancy. Journal of Molecular Endocrinology 22 91-101. (doi:10.1677/jme.0. 0220091)

Dey SK, Lim H, Das SK, Reese J, Paria BC, Daikoku T \& Wang H 2004 Molecular cues to implantation. Endocrine Reviews 25 341-373. (doi:10.1210/er.2003-0020)

Frank GR, Brar AK, Cedars MI \& Handwerger S 1994 Prostaglandin $E_{2}$ enhances human endometrial stromal cell differentiation. Endocrinology 134 258-263. (doi:10.1210/endo.134.1.7506205)

Hochbaum D, Barila G, Ribeiro-Neto F \& Altschuler DL 2011 Radixin assembles cAMP effectors Epac and PKA into a functional cAMP compartment: role in CAMP dependent cell proliferation. Journal of Biological Chemistry 286 859e66. (doi:10.1074/jbc.M110.163816) 
Kawasaki H, Springett GM, Mochizuki N, Toki S, Nakaya M, Matsuda M, Housman DE \& Graybiel AM 1998 A family of cAMP-binding proteins that directly activate Rap1. Science 282 2275-2279. (doi:10.1126/ science.282.5397.2275)

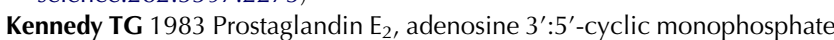
and changes in endometrial vascular permeability in rat uteri sensitized for the decidual cell reaction. Biology of Reproduction 29 1069-1076. (doi:10.1095/biolreprod29.5.1069)

Kocieda VP, Adhikary S, Emig F, Yen JH, Toscano MG \& Ganea D 2012 Prostaglandin $\mathrm{E}_{2}$-induced IL-23p19 subunit is regulated by cAMP-responsive element binding protein and C/AATT enhancer-binding protein $\beta$ in bone marrow derived dendritic cells. Journal of Biological Chemistry 287 36922-36935. (doi:10.1074/jbc.M112.402958)

Kooistra MR, Dubé N \& Bos JL 2007 Rap1: a key regulator in cell-cell junction formation. Journal of Cell Science 120 17-22. (doi:10.1242/ jcs.03306)

Kusama K, Yoshie M, Tamura K, Kodaka Y, Hirata A, Sakurai T, Bai H, Imakawa K, Nishi H, Isaka K et al. 2013 Regulation of decidualization in human endometrial stromal cells through exchange protein directly activated by cyclic AMP (Epac). Placenta 34 212-221. (doi:10.1016/j. placenta.2012.12.017)

Kusama K, Yoshie M, Tamura K, Nakayama T, Nishi H, Isaka K \& Tachikawa E 2014 The role of exchange protein directly activated by cyclic AMP 2-mediated calreticulin expression in the decidualization of human endometrial stromal cells. Endocrinology 155 240-248. (doi:10.1210/en.2013-1478)

Lim HJ \& Wang H 2010 Uterine disorders and pregnancy complications: insights from mouse models. Journal of Clinical Investigation $\mathbf{1 2 0}$ 1004-1015. (doi:10.1172/JCl41210)

Mantena SR, Kannan A, Cheon YP, Li Q, Johnson PF, Bagchi IC \& Bagchi MK 2006 C/EBP $\beta$ is a critical mediator of steroid hormone-regulated cell proliferation and differentiation in the uterine epithelium and stroma. PNAS 103 1870-1875. (doi:10.1073/pnas.0507261103)

Matsumoto H, Daikoku T, Wang H, Sato E \& Dey SK 2006 Differential expression of ezrin/radixin/moesin (ERM) and ERM-associated adhesion molecules in the blastocyst and uterus suggests their functions during implantation. Biology of Reproduction 70 729-736. (doi:10.1095/ biolreprod.103.022764)

Pakrasi PL \& Jain AK 2008 Cyclooxygenase-2 derived PGE $_{2}$ and PGI2 play an important role via EP2 and PPARdelta receptors in early steps of oil induced decidualization in mice. Placenta 29 523-530. (doi:10.1016/ j.placenta.2008.03.001)

Papay KD \& Kennedy TG 2000 Characterization of temporal and cell-specific changes in transcripts for prostaglandin $\mathrm{E}_{2}$ receptors in pseudopregnant rat endometrium. Biology of Reproduction 62 1515-1525. (doi:10.1095/ biolreprod62.6.1515)

Paria BC, Song H \& Dey SK 2001 Implantation: molecular basis of embryo uterine dialogue. International Journal of Developmental Biology $\mathbf{4 5}$ $597-605$.

Petersen RK, Madsen L, Pedersen LM, Hallenborg P, Hagland H, Viste K, Døskeland SO \& Kristiansen K 2008 (cAMP)-mediated stimulation of adipocyte differentiation requires the synergistic action of Epac- and cAMP-dependent protein kinase-dependent processes. Molecular and Cellular Biology 28 3804e16. (doi:10.1128/MCB.00709-07)
Roby KF, Deb S, Gibori G, Szpirer C, Levan G, Kwok SC \& Soares MJ 1993 Decidual prolactin-related protein. Identification, molecular cloning, and characterization. Journal of Biological Chemistry 268 3136-3142.

de Rooij J, Zwartkruis FJ, Verheijen MH, Cool RH, Nijman SM, Wittinghofer A \& Bos JL 1998 Epac is a Rap1 guanine-nucleotideexchange factor directly activated by cyclic AMP. Nature 396 474-477. (doi:10.1038/24884)

Soares MJ 2004 The prolactin and growth hormone families: pregnancy-specific hormones/cytokines at the maternal-fetal interface. Reproductive Biology and Endocrinology 2 51. (doi:10.1186/14777827-2-51)

Sterneck E, Tessarollo L \& Johnson PF 1997 An essential role for C/EBP $\beta$ in female reproduction. Genes and Development 11 2153-2162. (doi:10. 1101/gad.11.17.2153)

Sugimoto Y \& Narumiya S 2007 Prostaglandin E receptors. Journal of Biological Chemistry 282 11613-11617. (doi:10.1074/jbc.R600038200)

Tamura K, Hara T, Yoshie M, Irie S, Sobel A \& Kogo H 2003 Enhanced expression of uterine stathmin during the process of implantation and decidualization in rats. Endocrinology 144 1464-1473. (doi:10.1210/en. 2002-220834)

Vilar-Rojas C, Castro-Osuna G \& Hicks JJ 1982 Cyclic AMPand cyclic GMP in the implantation site of the rat. International Journal of Fertility 27 56-59.

Wang W, Taylor RN, Bagchi IC \& Bagchi MK 2012 Regulation of human endometrial stromal proliferation and differentiation by C/EBP $\beta$ involves cyclin E-cdk2 and STAT3. Molecular Endocrinology 26 2016-2030. (doi:10.1210/me.2012-1169)

Yarwood SJ, Borland G, Sands WA \& Palmer TM 2008 Identification of CCAAT/ enhancer-binding proteins as exchange protein activated by cAMP-activated transcription factors that mediate the induction of the SOCS-3 gene. Journal of Biological Chemistry 283 6843e53. (doi:10.1074/ jbc.M710342200)

Yee GM \& Kennedy TG 1993 Prostaglandin $E_{2}$, cAMP and cAMP-dependent protein kinase isozymes during decidualization of rat endometrial stromal cells in vitro. Prostaglandins 46 117-138. (doi:10.1016/00906980(93)90038-9)

Yoshie M, Tamura K \& Kogo H 2004 Differential localization of decidual stathmin during pregnancy in rats. Placenta 25 449-455. (doi:10.1016/ j.placenta.2003.10.007)

Yoshie M, Miyajima E, Kyo S \& Tamura K 2009 Stathmin, a microtubule regulatory protein, is associated with hypoxia-inducible factor- $1 \alpha$ levels in human endometrial and endothelial cells. Endocrinology $\mathbf{1 5 0}$ 2413-2418. (doi:10.1210/en.2008-1333)

Yoshie M, Kaneyama K, Kusama K, Higuma C, Nishi H, Isaka K \& Tamura K 2010 Possible role of the exchange protein directly activated by cyclic AMP (Epac) in the cyclic AMP-dependent functional differentiation and syncytialization of human placental BeWo cells. Human Reproduction 25 2229-2238. (doi:10.1093/humrep/deq190)

Received 18 December 2013

First decision 13 January 2014

Revised manuscript received 24 February 2014

Accepted 27 February 2014 